\title{
IV. EL MEDIO AMBIENTE COMO DERECHO DIFUSO Y SU PROTECCIÓN PROCESAL EN MÉXICO.
}

\author{
Dra. María Auxiliadora MORENO VALENZUELA \\ Mta. Julia ROMERO OCHOA
}

SUMARIO 1. Introducción, 2. El medio ambiente: concepto, 3. El medio ambiente como derecho difuso, 4. El derecho procesal constitucional, y la defensa de los derechos difusos en Iberoamérica. 5. Conclusiones

\section{Introducción}

Los avances en la tecnología que han incrementado la producción de bienes y servicios, provocando el desarrollo inusitado del consumo humano, han generado a la vez, el surgimiento de redes de relaciones entre los hombres cada vez más complejas. Dentro de la complejidad de estas relaciones, el hombre ha tenido la necesidad de cambiar sus ideas y concepciones, a fin de tratar de explicarse desde todos los ámbitos disciplinarios, no sólo su razón de ser, sino también la forma en que interactúa con los demás hombres y los otros seres vivos que lo rodean.

Estamos en la era que ha sido llamada, de la tercera revolución tecnológica, los cambios en todas las áreas del conocimiento humano se dan todos los días. El uso de la biotecnología y las comunicaciones permite al hombre, pensar en la inmortalidad, vía transformaciones genéticas. Sin embargo, a la par de los beneficios que puedan traer estos cambios para el hombre en su salud, en su hábitat, surgen los conflictos del uso y abuso indiscriminado de los recursos naturales, que conforman su entorno. La certeza de que al menos hasta el día de hoy sólo contamos con este entorno para desarrollarnos (se busca lograr en el futuro el poder habitar otros planetas) como seres humanos integrales, ha provocado la necesidad de regular a nivel mundial las relaciones del hombre con su medio ambiente, en aras de conservarlo.

Las exigencias del desarrollo han provocado una trasformación acelerada, (y en muchas ocasiones irresponsable) del entorno vital, la protección del medio ambiente, surge como una condición del hombre, para su propia supervivencia.

Además de regular las relaciones de los hombres entre sí, es necesario, también reglamentar las relaciones del hombre con la naturaleza. La disciplina jurídica se ha tenido que avocar a la búsqueda de nuevas figuras jurídicas, al remplazo de viejas concepciones y doctrinas, provocando con esto los cambios de textos legales y constitucionales. El objetivo es enfrentar la nueva situación, formulando ideas y construyendo nuevos caminos legales que permitan dar solución a la problemática nacida de un entorno que requiere la restructuración y en su caso el cambio de las estructuras legales pertinentes.

En este contexto emergen nuevos derechos, que son reconocidos a nivel internacional, como derechos humanos de tercera generación, también llamados derechos difusos o colectivos y donde se encuentran contemplados, el derecho al desarrollo, el derecho a un medio ambiente sano, el derecho de los consumidores, el derecho a la calidad de vida, la libertad informática, el derecho a la autodeterminación de los pueblos, el derecho de propiedad sobre el patrimonio común de la humanidad, entre otros.

Los derechos de tercera generación persiguen la protección de los llamados intereses o derechos difusos e intereses o derechos colectivos. Es decir de aquellos intereses que no se encuentran ubicados en un sujeto determinado, sino que se encuentran difundidos o diseminados entre todos los integrantes de una comunidad en específico o de la sociedad en su conjunto. 
Estamos ante la presencia de un tipo de derechos que se les ejerce colectivamente, porque su titular es una colectividad, de difícil determinación, aunque hay que precisar que si bien ella es la afectada, puede también lesionar derechos de personas en particular.

El derecho a la participación social en la toma de decisiones en materia ambiental, sin lugar a dudas tiene como presupuesto la coexistencia y el ejercicio de dos derechos fundamentales: el derecho a la información y el derecho a la democracia. Estas características primordialmente colectivas de los llamados derechos difusos, generan un conflicto procesal al momento de plantearse su defensa ante los tribunales. Se trata de determinar quién o quiénes están legitimados para accionar ante la justicia; por eso a pesar de que estos derechos están constitucionalizados en casi todos los países del mundo, no ha sido suficiente esto para garantizar su ejercicio. En la búsqueda de formas que permitan la tutela jurisdiccional de estos derechos, cobra importancia una joven disciplina jurídica: el derecho procesal constitucional.

En este trabajo me propongo explorar la problemática referente a la tutela de los derechos difusos, tomando como punto de reflexión el derecho al medio ambiente. Iniciaré conceptualizando el derecho al medio ambiente y su naturaleza como derecho difuso; posteriormente haré un recorrido por la legislación Latinoamericana en relación con este tema, para concluir con la situación del medio ambiente en nuestro país y su relación con el derecho procesal constitucional.

\section{El medio ambiente: concepto}

El derecho de las personas al medio ambiente lo encontramos en casi todas las legislaciones del mundo. La importancia de este derecho adquiere diferentes modalidades en dichas legislaciones dependiendo de la forma en que cada uno de esos países lo concibe.

En México el derecho al medio ambiente se encuentra establecido en el Artículo 40 constitucional, donde se señala: "Toda Persona tiene derecho a un medio ambiente adecuado para su desarrollo y bienestar".

Por su parte Ley General del Equilibrio Ecológico y la Protección al Ambiente, establece la definición del medio ambiente señalando: "El conjunto de elementos naturales y artificiales o inducidos por el hombre que hacen posible la existencia y desarrollo de los seres humanos y demás organismos vivos que interactúan en un espacio y tiempo determinados".

\section{El medio ambiente como derecho difuso}

La idea de proteger jurídicamente bienes que no puede ser personalizados en tanto no son propiedad de nadie en particular, se hace evidente a partir del surgimiento de los derechos humanos llamados de tercera generación y en donde se encuentran, "el derecho al medio ambiente, el derecho de los consumidores, el derecho al desarrollo, el derecho a la calidad de vida, la libertad informática, el derecho a la autodeterminación de los pueblos, el derecho de propiedad sobre el patrimonio común de la humanidad, el derecho a la paz, etcétera". ${ }^{28}$

La diferencia en cuanto a los derechos subjetivos es radical, en cuanto a que, en éstos, su sola existencia presupone el otorgamiento a su titular de un poder o facultad de disposición, en cambio, cuando hablamos de la tutela de los derechos difusos, no estamos en presencia de es hilo vinculante, lo cual ha generado una serie de discusiones entre los juristas, relativas a la legitimación de estos derechos. Es decir, con el reconocimiento de estos derechos difusos se trastocan las características individualistas de la tutela de los derechos subjetivos. No estamos ante la presencia de un solo y único individuo litigante, sino ante un grupo de individuos que tienen como punto de unión la solidaridad.

\footnotetext{
${ }^{28}$ FERRER MAC-GREGOR, Eduardo, et al., (coord.), "El Acceso a la Justicia de los Intereses de Grupo", en Derecho Procesal Constitucional, 3 Vols., México, Porrúa-Colegio de Secretarios de la Suprema Corte de Justicia de la Nación, A. C., 2001.Pp. 345.
} 
Se plantea entonces que los derechos subjetivos, acorde a las exigencias de una sociedad de masas, protejan, a partir del surgimiento de nuevos derechos, una serie de bienes nuevos y (con titulares más amplios), propios de una sociedad de masas.

Con el surgimiento de la tercera generación de los derechos humanos, estamos hablando de la creación de nuevas acciones que protejan un hábitat adecuado, el desarrollo de los pueblos, el crecimiento con equilibrio, la salud, los derechos de las minorías, las mujeres, los discapacitados, los consumidores, los grupos indígenas, etc., olvidados por la fuerza de esta tercera revolución tecnológica.

¿Pero que son los derechos difusos? Es el Código Brasileño el que aporta una de las definiciones legales más completas sobre este tipo de derechos. El artículo 810 señala en su "Párrafo único. La defensa colectiva será ejercida cuando se trate de: I. Intereses o Derechos Difusos entendidos para los efectos de este Código los transindividuales de naturaleza indivisible de que sean titulares personas indeterminadas y ligadas por circunstancias de hecho". ${ }^{29}$

En ese mismo artículo, el citado Código brasileño define en su fracción II, los intereses o derechos colectivos, diferenciándolos, de esta manera, de los derechos difusos. Así, establece: "Intereses o derechos colectivos, entendidos para efectos de este Código, los transindividuales de naturaleza indivisible de que sea titular un grupo, categoría o clase de personas ligadas entre sí o a la parte contraria por una relación jurídica básica;". ${ }^{30}$

¿Pero a que se refiere el código brasileño cuando hace alusión en el mencionado artículo a derechos transindividuales?

El concepto de "derecho transindividual", dice Gidi en el texto señalado:

Solamente significa que el derecho no es individual. Existe como una entidad distinta de cualquier individuo o grupo de individuos. Esta más allá de lo individual y sin embargo no sólo es una mera colección de derechos individuales. Un derecho "transindividual", tal como la pureza del aire, la limpieza de un río, la veracidad de los anuncios o la seguridad de los productos pertenece a la comunidad como un todo y no a un individuo específico o al gobierno. ${ }^{31}$

Por otra parte, la Sala Constitucional del Tribunal Supremo de Justicia de la República Bolivariana de Venezuela, estableció su conceptualización sobre los derechos e intereses difusos o colectivos, con fecha 30 de junio de 2000, mediante ponencia del Magistrado Dr. Jesús Eduardo Cabrera.

El derecho o interés difuso vincula a personas que no se conocen entre si, que individualmente pueden carecer de nexo o relaciones jurídicas entre ellas, que en principio son indeterminadas, unidas sólo por la misma situación de daño o peligro en que se encuentran como miembros de una sociedad y por el derecho que todos tienen a que se les resguarde su calidad de vida. Así, debe existir un vínculo común, así no sea jurídico, entre quien acciona para lograr la aplicación de una norma fundamental y la sociedad o el segmento de ella que al igual que el accionante se ve afectado en tales derechos por una acción u omisión emanada de los órganos del Estado o de los particulares que atenta contra su calidad de vida. ${ }^{32}$

\footnotetext{
${ }^{29}$ GIDI, Antonio, “Acciones de Grupo y “Amparo Colectivo" en Brasil, en Derecho Procesal Constitucional, Eduardo, Ferrer Mac-Gregor, et al., (coord.), 3 Vols., México, Porrúa-Colegio de Secretarios de la Suprema Corte de Justicia de la Nación, A. C., 2002, Pp. 2057

${ }^{30}$ Idem.

${ }^{31}$ Ibidem, Pp. 2031

32 EDUARDO CABRERA, Jesús, "sala constitucional del tribunal supremo de justicia de venezuela, establece noción de los derechos e intereses difusos o colectivos y la legitimación para su ejercicio" en http://www.badellgrau.com/sentintereses.htm., fecha de consulta: 12 de agosto del 2003. La Sala Constitucional Venezolana, establece además la diferencia entre derechos difusos y derechos colectivos Revista Jurídica del Departamento de Derecho Academia de Derecho Administrativo Tercera Época. Año 2. No 2. Vol. 1.Enero-Junio 2010
} 
El derecho al medio ambiente es un Derecho humano de tercera generación, también llamado derecho o interés difuso, en tanto que, sus titulares son personas indeterminadas y ligadas entre sí por circunstancias de hecho. Así, nos dice Gidi, la contaminación de una bahía, representa un buen ejemplo de derechos difusos. "El derecho a un ambiente sano pertenece a cada uno y al mismo tiempo a ninguno. La bahía no pertenece a alguien en particular; la violación de sus aguas daña a la comunidad como un todo y la limpieza de éstas beneficia al grupo en su conjunto (indivisibilidad)". ${ }^{33}$

\section{El derecho procesal constitucional y la defensa de los derechos difusos en iberoamérica}

Para Fix-Zamudio, el derecho procesal constitucional tiene como objeto esencial el análisis de las garantías constitucionales, es decir, los instrumentos predominantemente procesales que están dirigidos a la reintegración del orden constitucional cuando el mismo ha sido desconocido o violado por órganos del poder. Es la disciplina que se encarga de estudiar a los órganos y las normas procesales que deciden controversias de carácter constitucional. ${ }^{34}$

El derecho procesal constitucional en México, está integrado por el juicio de amparo, las controversias constitucionales, las acciones de inconstitucionalidad, el juicio para la protección de los derechos políticos, el juicio de revisión electoral, el juicio político, el procedimiento de investigación de la Suprema Corte de Justicia y el procedimiento ante los organismos de derechos humanos.

Todos estos procesos tienen en común estar contemplados en nuestra constitución y que tienen como finalidad su protección, ahí radica su diferencia con los demás procesos de orden, civil, penal, etc.

Los antecedentes de estos instrumentos de control constitucional, son muy diversos, así como las legislaciones que les dieron origen, pero es apenas en épocas recientes, que todos ellos se han conformado en una sola disciplina a la que se ha llamado derecho procesal constitucional.

\section{Ahora bien ¿cual es el contenido del derecho procesal constitucional?}

-Jurisdicción constitucional de la libertad. Es la que se refiere a la tutela jurídica de los derechos humanos establecidos en las diversas constituciones, así como a la de los contenidos en los tratados internacionales.

-Jurisdicción constitucional orgánica. "Es aquella dirigida a la protección directa de las disposiciones y principios constitucionales que consagran las atribuciones de los diversos órganos del poder". ${ }^{35}$

-Jurisdicción constitucional trasnacional. Es la encargada de proteger las normas que pertenecen al campo trasnacional y que pueden clasificarse en: a) los ordenamientos constitucionales internos de las

señalando: "Advierte la Sala que si bien la Constitución no establece distinción alguna entre los intereses difusos o colectivos, lo que pudiera dar pie para pensar que forman una sola categoría, es lo cierto que tales figuras son distintas entre sí. Así, mientras el derecho o interés difuso se refiere a un bien que atañe a un conglomerado social, genérico e indeterminado, el interés colectivo comporta un bien referido a un sector poblacional determinado e identificable (aunque no cuantificable). El interés colectivo surge de un prestación que puede ser concreta pero exigible por personas no individualizables. Tal es el caso de las lesiones a grupos profesionales, vecinales, gremios o a los habitantes de un área determinada."

${ }^{33}$ Idem.

${ }^{34}$ FIX-ZAMUDIO, Héctor, Breves Reflexiones sobre el Concepto y el Contenido del Derecho Procesal Constitucional, presentada como material de estudio en el curso, Derecho Procesal Constitucional impartido en el doctorado de Derecho Público. Junio 2003, pp. 169

${ }^{35}$ Ibedem, pp.188 
reglas y principios del derecho internacional generalmente reconocidas, y, b) Los tratados o convenios propiamente dichos. ${ }^{36}$

El surgimiento de los derechos humanos de la tercera generación evidencia la necesidad fortalecer todas aquellas iniciativas y esfuerzos encaminados a fortalecer aquellos mecanismos de control constitucional que tienen como fin salvaguardar los derechos fundamentales insertos en los diversos textos constitucionales, así como los derechos humanos establecidos en todos los instrumentos internacionales, estén o no constitucionalizados.

En este contexto, cabe preguntarse ¿quiénes son los encargados de ejercer las acciones que derivan de los intereses difusos de tercera generación?, ¿basta con que éstos derechos estén contemplados en las constituciones para que puedan ejercerse?, ¿cómo los titulares del derecho a disfrutar de un medio ambiente sano, pueden defenderlo ante los tribunales?

Contestando a la primera pregunta el Dr. Ferrer Mac-Gregor nos dice: "no es suficiente el reconocimiento de dichos intereses por la legislación, si no existen los mecanismos procesales adecuados para su protección jurisdiccional”. ${ }^{37}$

El problema del acceso a la justicia de los derechos difusos y colectivos tiene ver, con quienes son los legitimados jurídicamente para defender estos derechos ante los tribunales.

En la Legitimación común o ordinaria, se actúa con base en la titularidad de un derecho subjetivo propio; en la legitimación extraordinaria, que acepta la doctrina, se ejercita un derecho de otro en nombre de otro y en beneficio propio; en los intereses de grupo, en cambio, encontramos una legitimación sui generis, en tanto que si bien se actúa afirmando la titularidad de un derecho o interés propio, éstos se encuentran confundidos con el resto del conglomerado o grupo, por lo que el reclamo en realidad se hace también a nombre de todos los posibles afectados por un determinado hecho o acto. De ahí la importancia de la acción derivada de este tipo de intereses, pues su actuación trasciende del propio interés para proyectarse en el interés de toda la colectividad o grupo que asume. ${ }^{38}$

El tema de quién o quienes están legítimamente facultados para defender estos derechos ante los tribunales, ha sido resuelto de diversas maneras en las distintas legislaciones que lo han hecho, presentándose estas soluciones mediante dos grandes vertientes, para Ferrer Ma-Gregor, la primera es la seguida por legislaciones europeas y estadounidenses, que consiste "en la habilitación de nuevos mecanismos procesales, particularmente mediante la atribución de personería a las asociaciones de titulares de intereses difusos; y la segunda, a través de las instituciones procesales ya existentes" ${ }^{39}$ En los países latinoamericanos predomina la segunda vertiente.

\section{Argentina}

En Argentina el artículo 43 Constitucional otorga legitimación activa para la defensa de los derechos difusos y colectivos al Defensor del Pueblo y a las asociaciones que persigan estos fines, estableciendo como requisito que estén registradas conforme a la ley. ${ }^{40}$

\footnotetext{
${ }^{36}$ FIX-ZAMUDIO, Héctor, Breves Reflexiones sobre...Op. Cit. Pp. 190

${ }^{37}$ FERRER MAC-GREGOR, Eduardo, "El Acceso a la Justicia..." Op. Cit. Pp. 356

${ }^{38}$ FERRER MAC-GREGOR, Eduardo, “El Acceso a la Justicia..." Op. Cit. Pp. 349

${ }^{39}$ Idem.

${ }^{40}$ FERRER MAC-GREGOR, Eduardo, “El Acceso a la Justicia..." Op. Cit. Pp. 352

Revista Jurídica del Departamento de Derecho Academia de Derecho Administrativo 
La reforma a la Constitución argentina ha incorporado la figura del llamado "amparo colectivo" que puede ser interpuesto "contra cualquier forma de discriminación y en lo relativo a los derechos que protegen al ambiente, a la competencia, al usuario y al consumidor, así como a los derechos de incidencia colectiva en general" (art. 43, 20 párrafo). ${ }^{41}$

Brasil

La Constitución del Brasil, contempla la acción popular y la interpretación jurisprudencial de los tribunales brasileños, para la defensa de los derechos difusos y colectivos, incluyendo, por supuesto, el derecho al medio ambiente. Prevé también el "mandamiento de seguridad" colectivo, para este mismo fin.

Chile

La Constitución chilena, tutela el derecho al medio ambiente, contra un acto arbitrario de una autoridad o particular.

Colombia

La Constitución de Colombia contiene un capítulo sobre los derechos colectivos y del ambiente, en donde señala como formas de tutela de estos derechos, a las acciones populares y a la responsabilidad civil objetiva para exigir la indemnización por el daño cometido contra los derechos o intereses colectivos.

Asimismo dicha Constitución, caracteriza a las acciones populares como "aquéllas acciones interpuestas por un número plural o un conjunto de personas que reúnan condiciones uniformes respecto de una misma causa que originó perjuicios individuales para dichas personas. Las condiciones uniformes deben tener también lugar respecto de todos los elementos que configuran la responsabilidad"42

Ecuador

La Constitución de Ecuador, extiende la legitimación para ampararse a cualquier persona, en nombre propio o en representación de una colectividad.

\section{Costa Rica}

La Carta Magna de Costa Rica, contempla la denuncia por actos que afecten el medio ambiente y para reclamar la reparación del daño.

Paraguay

La constitución de Paraguay, prevé la tutela de los derechos difusos, otorgando legitimidad a todas las personas, individual y colectivamente para reclamar ante los tribunales la defensa de los derechos difusos.

\footnotetext{
${ }^{41}$ SABSAY, Daniel Alberto, La Protección del Medio Ambiente a través del llamado Amparo Colectivo, a propósito de un fallo de la Justicia Entrerriana, en http://www.farn.org.ar/docs/a06/art6.html

42 OVAlle faVela, José “Acciones Populares y Acciones para la tutela de los Intereses Colectivos", en Boletín Mexicano, núm. 16 http://www.juridicas.unam.mx/publica/rev/boletin/cont/107/art/art6.htm fecha de consulta 28 de julio 2003.
} 
Venezuela

Efectivamente tal y como lo señala el Dr. Ferrer Mac-Gregor, la Constitución Venezolana merece mención especial, en tanto que los tratados sobre derechos humanos tienen jerarquía constitucional y prevalecen sobre la propia constitución venezolana en caso de contener normas sobre goce y ejercicio más favorables, siendo, además, "de aplicación inmediata y directa por los tribunales y demás órganos del poder público (art. 23)",43

Por otra parte la Sala Constitucional del Tribunal Supremo de Justicia de esa nación, el $\mathbf{3 0}$ de junio de 2000, determino la naturaleza jurídica de los derechos difusos, señalando que corresponderá "a la Sala Constitucional el conocimiento de las acciones que tengan por objeto la tutela de tales derechos, mientras la ley no lo atribuya a otro tribunal. En consecuencia, ni el contencioso administrativo, ni la justicia ordinaria o especial son competentes, a juicio de la Sala, para declarar y hacer efectivos estos derechos salvo que la ley disponga lo contrario." ${ }^{44}$

\section{Guatemala}

“En el proyecto de Código Procesal General de Guatemala se prevén acciones para la tutela de intereses difusos, tales como el medio ambiente, de valores culturales e históricos, así como de intereses "que pertenezcan a un grupo indeterminado de personas" (artículo 63.1). También se contemplan las acciones de grupo para cuando "existan cuestiones de hecho o de derecho que sean comunes a las personas pertenecientes al litisconsorcio" (artículo 63.2)." ${ }^{45}$

Cada uno de estos ejemplos, demuestra el interés de los países Iberoamericanos por avanzar hacia el fortalecimiento de una protección procesal constitucional, para los derechos humanos denominados de tercera generación

\section{México}

La reforma al artículo 4to. Constitucional establece el derecho de las personas a un medio ambiente al señalar: "Toda persona tiene derecho a disfrutar de un medio ambiente adecuado para su desarrollo y bienestar" (lo cual implica el derecho a una calidad de vida y derecho al medio ambiente, relacionados directamente con los intereses difusos y colectivos), y que al comprenderse dentro de las garantías individuales pueden ser objeto del juicio de amparo."46

Para Ferrer Mac-Gregor, el que los tribunales mexicanos, se nieguen a proteger judicialmente el derecho al medio ambiente a pesar de encontrarse reconocido como un derecho fundamental, tiene que ver principalmente con la falta de regulación expresa de las formas o maneras de cómo deberán ser tutelados. Es decir no se estipularon los mecanismos para su defensa, a fin de hacerlo exigible ante los tribunales, no existen lo que Ferrajoli llama las garantías secundarias o garantías procesales.

\footnotetext{
${ }^{43}$ FERRER MAC-GREGOR, Eduardo, “El Acceso a la Justicia..." Op. Cit. Pp. 353

${ }^{44}$ EDUARDO CABRERA, Jesús, Sala Constitucional del Tribunal Supremo de Justicia de Venezuela, Establece Noción de los Derechos e Intereses Difusos o Colectivos y la Legitimación para su Ejercicio en http://www.badellgrau.com/sentintereses.htm., fecha de consulta: 12 de agosto del 2003.

${ }^{45}$ OVALLE FAVELA, José "Acciones Populares y ... Op. Cit.

${ }^{46}$ FERRER MAC-GREGOR, Eduardo, “El Acceso a la Justicia...” Op. Cit. Pp. 355

Revista Jurídica del Departamento de Derecho Academia de Derecho Administrativo 
$Y$ eso es evidente cuando revisamos la experiencia jurídica de aquellos miembros de la sociedad civil mexicana, que al acudir ante los tribunales solicitando el amparo y protección de la justicia federal, se han encontrado con la negativa judicial.

"La mayoría de los jueces de distrito han negado la posibilidad de acceder vía amparo, al considerar la falta de interés jurídico del quejoso, motivando el sobreseimiento en el juicio con base en la fracción V del artículo 73 de la Ley de Amparo. Los menos han otorgado amparos o la suspensión del acto reclamado". ${ }^{47}$

El que este derecho al medio ambiente, al igual que los otros derechos difusos y colectivos, no gocen según el criterio de los jueces de la naturaleza propia de un derecho subjetivo; no puede ser, o no debiera ser un obstáculo para el acceso a la justicia de estos nuevos derechos supraindividuales. Se requiere entonces que el legislador diseñe la forma y mecanismos que hagan exigible este derecho, mediante el establecimiento de instrumentos procesales para su protección jurisdiccional.

Se precisa una revisión de nuestro Juicio de Amparo, enfocada fundamentalmente a los aspectos que permitan establecer quien o quienes son los titulares de estos derechos y las formas de acreditar su legitimación; a fin de permitirles la defensa del interés difuso o colectivo; dotándolo de un enfoque más social, menos individualista, acorde con la tendencia a nivel mundial de un constitucionalismo garantista, protector de los derechos fundamentales.

La ley general del equilibrio ecológico y la protección al ambiente.

La Ley General del Equilibrio Ecológico y la Protección al Ambiente, en su artículo 80 establece el recurso de revisión, como un medio de defensa del derecho a un medio ambiente adecuado, legitimando, para interponerlo a las personas físicas y morales afectadas por alguna resolución o acto de autoridad que violente este derecho. Señala el citado artículo:

Tratándose de obras o actividades que contravengan las disposiciones de esta Ley, los programas de ordenamiento ecológico, las declaratorias de áreas naturales protegidas o los reglamentos y normas oficiales mexicanas derivadas de la misma, las personas físicas y morales de las comunidades afectadas tendrán derecho a impugnar los actos administrativos correspondientes, así como a exigir que se lleven a cabo las acciones necesarias para que sean observadas las disposiciones jurídicas aplicables, siempre que demuestren en el procedimiento que dichas obras 0 actividades originan o pueden originar un daño a los recursos naturales, la flora o la fauna silvestre, la salud pública o la calidad de vida. Para tal efecto, deberán interponer el recurso administrativo de revisión a que se refiere este capítulo. ${ }^{48}$

Este procedimiento señalado en la Ley General del Equilibrio Ecológico y la Protección al Ambiente, establece como titulares de este derecho ambiental, a los miembros de las comunidades indígenas, regulando de esta forma la participación social en materia ambiental.

La ley en comento contempla, además, en el Capitulo séptimo, artículo 189 la denuncia popular, señalando que:

Toda persona, grupo social, organización no gubernamental, asociación y sociedad podrán denunciar ante la Procuraduría Federal de Protección al Ambiente o ante otras autoridades, todo hecho que dañe el ambiente o los recursos naturales, o que contravenga las disposiciones de la LGEEPA y de los

\footnotetext{
${ }_{48}^{47}$ Idem LEY GENERAL DEL EQUILIBRIO ECOLÓGICO Y PROTECCIÓN AL AMBIENTE (“LGEEPA"), en http://www.semarnat.gob.mx/PortalNormatividad2/menuPortalNorm.php

Revista Jurídica del Departamento de Derecho Academia de Derecho Administrativo Tercera Época. Año 2. No 2. Vol. 1.Enero-Junio 2010
} 
demás ordenamientos que regulen materias relacionadas con la protección del ambiente y la preservación y restauración del equilibrio ecológico.

Este procedimiento se fortalece con la obligación de la Secretaría del Medio Ambiente de informar al denunciante dentro de un término de 10 días sobre el trámite que le ha dado a su denuncia, y en caso de declararse incompetente para conocer la queja, de turnarla a la autoridad competente, notificando al denunciante, siendo así que el denunciante se encuentra siempre informado sobre la aportación o denuncia que realizo. ${ }^{49}$

Creo que este procedimiento es un ejemplo de una acercamiento del derecho mexicano a la protección de los intereses y derechos difusos, sin embargo, la fuerza coercitiva de este procedimiento se ve nulificada al no existir una sanción específica para los que violenten el derecho al medio ambiente.

\section{Conclusiones.}

Se hace necesario que el derecho procesal, ofrezca la posibilidad de defensa de los derechos o intereses difusos y colectivos, a fin de resolver de la mejor manera los conflictos sociales. Se debe buscar rebasar el marco de la protección jurisdiccional de los derechos subjetivos individuales, para ampliar la protección de intereses privados hacia la protección de los intereses colectivos.

Actualmente existe en México, un proyecto de reforma al artículo 4 de la Ley de Amparo que pretende ampliar la legitimación activa del quejoso, se pretende crear un figura jurídica denominada "interés legítimo", adicionando el capítulo segundo de la ley que habla de la capacidad y personalidad, estableciendo claramente quienes estarán legitimados para la defensa de los intereses y derechos difusos, ante los tribunales. Si esta propuesta de reforma se materializa, estaremos avanzando en la construcción de un constitucionalismo garantista, que se convertirá a la vez, en el sustento jurídico de un una sociedad más democrática. 
Bibliografía

ARÉVAlo AlVAREZ, Luis Ernesto, El concepto jurídico de los derechos humanos, México, Ed., Universidad Iberoamericana Santa fe, Universidad Iberoamericana Golfo Centro, Centro de Derechos Humanos Agustín Pro, 1997.

BurgoA, Ignacio, El juicio de amparo, 36ạ ed., actualizada, México D.F., Porrúa, 1999.

CANOSA USERA, Raúl, “APUNTES PARA LA DELIMITACIÓN DEL DERECHO SUBJETIVO AMBIENTAL, en Derecho Procesal Constitucional, México, Porrúa, 2001.

Ferrer MAC-Gregor, Eduardo, La acción constitucional de amparo en México y España. Estudio de derecho comparado, 2a ed., México D.F., Porrúa, 2000.

FERRER MAC-GREGOR, Eduardo, et al., (coord.), "El Acceso a la Justicia de los Intereses de Grupo", en Derecho Procesal Constitucional, 3 Vols., México, Porrúa-Colegio de Secretarios de la Suprema Corte de Justicia de la Nación, A. C., 2002

FERRER MAC-GREGOR, Eduardo, Los tribunales constitucionales en Iberoamérica, México, Ed., Fundap, , 2002.

FERRER MAC-GREGOR, Eduardo, La nueva Sala constitucional en el Estado de Veracruz, presentada como material de estudio en el curso, Derecho Procesal Constitucional impartido en el doctorado de Derecho Público. Junio 2003.

FIX-ZAMUDIO, Héctor, Salvador Valencia Carmona, Derecho Constitucional Mexicano, México, Porrúa, 2003.

GIDI, Antonio, “Acciones de Grupo y "Amparo Colectivo”, en Brasil. La Protección de los Derechos Difusos, Colectivos e Individuales Homogéneos", en Derecho Procesal Constitucional, Eduardo Ferrer Mac-Gregor et al., (coord.), 3 Vols., México, Porrúa-Colegio de Secretarios de la Suprema Corte de Justicia de la Nación, A. C., 2002.

GUTIÉRREZ de CABIEDES hidAlgo de CAVIEDES, Pablo, “Derecho Procesal Constitucional y Protección de los Intereses Colectivos y Difusos", en Derecho Procesal Constitucional, Eduardo Ferrer Mac-Gregor et al., (coord.), 3 Vols., México, Porrúa-Colegio de Secretarios de la Suprema Corte de Justicia de la Nación, A. C., 2002.

HITTERS, Juan Carlos, "Algo más sobre el Proceso Trasnacional”, en Derecho Procesal Constitucional, Eduardo Ferrer Mac-Gregor et al., (coord.), 3 Vols., México, Porrúa-Colegio de Secretarios de la Suprema Corte de Justicia de la Nación, A. C., 2002.

NOGUEIRA ALCALÁ, Humberto, “La Soberanía, las Constituciones y los Tratados Internacionales en Materia de Derechos Humanos: América Latina y Chile", en Derecho Procesal Constitucional, Eduardo Ferrer Mac-Gregor et al., (coord.), 3 Vols., México, Porrúa-Colegio de Secretarios de la Suprema Corte de Justicia de la Nación, A. C., 2002.

Trueba Urbina, Alberto y Jorge Trueba Barrera, Nueva legislación de Amparo Reformada. Doctrina, textos y jurisprudencia.76a ed., México D.F., Porrúa, 2001.

Legislación

Revista Jurídica del Departamento de Derecho

Academia de Derecho Administrativo

Tercera Época. Año 2. No 2. Vol. 1.Enero-Junio 2010 
CONSTITUCIÓN POLÍTICA DE LOS ESTADOS UNIDOS MEXICANOS, 144ạ ed., México D.F., Porrúa, 2003.

LEY GENERAL Del EQUiLIBRIO ECOLÓGICO Y PROTECCIÓN AL AMBIENTE (“LGeEPA”), en http://www.semarnat.gob.mx/PortalNormatividad2/menuPortalNorm.ph

Internet

ALVARADO MARTínEZ, Israel, Algunas consideraciones en torno a los Delitos Ambientales en http://www.cddhcu.gob.mx/camdip/comlvii/comeco/foros/israel.htm

CABRERA, Jesús, Eduardo, Sala Constitucional del Tribunal Supremo de Justicia de Venezuela, Establece Noción de los Derechos e Intereses Difusos o Colectivos y la Legitimación para su Ejercicio en http://www.badellgrau.com/sentintereses.htm., fecha de consulta: 12 de agosto del 2003.

CARVAJAL ISUNZA, Gustavo, Residuos Industriales: Problemas y Contradicciones Jurídicas", en http://www.cce.org.mx/cespedes/publicaciones/revista/revista 4/residuos.htm

GOZAíNI, Osvaldo, "El desplazamiento de la Noción de Derecho Subjetivo por el de Acceso a la Justicia sin restricciones (sobre problemas actuales de la legitimación y el proceso judicial)", en revista jurídica http://www.juridicas.unam.mx/publica/rev/boletin/cont/83/art/art6.htm, fecha de consulta: 12 de agosto del 2003.

OVALLE FAVELA, José, "Acciones Populares y Acciones para la Tutela de los Intereses Colectivos, en Boletín Mexicano de Derecho Comparado, núm., 106, InfoJus Publicaciones, http://www.juridicas.unam.mx/publica/rev/boletin/cont/83/art/art6.htm, fecha de consulta: 12 de agosto del 2003.

OYARTE MARTÍNEZ, Rafael, "El Amparo Contra Particulares", en http://www.juridicas.unam.mx/publica/rev/boletin/cont/83/art/art6.htm

PÓLIT MONTES DE OCA, Berenice, La Legitimación Pasiva en la Acción de Amparo y la Protección de los Derechos Difusos $y \quad$ Colectivos, en http://www.juridicas.unam.mx/publica/rev/boletin/cont/83/art/art6.htm, fecha de consulta: 12 de agosto del 2003.

RODRíGUEZ, Sergio, Reseña del libro Derecho Procesal Constitucional Eduardo, Ferrer Mac-Gregor, (coord.), , 3 Vols., México, Porrúa-Colegio de Secretarios de la Suprema Corte de Justicia de la Nación, A. C., 2002. http://www.juridicas.unam.mx/publica/rev/cconst/cont/9/rb/rb12.htm

SABSAY, Daniel Alberto, "La Protección del Medio Ambiente a través del llamado Amparo Colectivo, a Propósito de un Fallo de la Justicia Entrerriana", en El Derecho. Tomo 167 (16/4/96), Buenos Aires, p. 61. Fecha de consulta 12 de agosto del 2003.http://www.farn.org.ar/docs/a06/art6.html

SIMÓN GÁLVEZ, Anna paola, La Participación Social en Materia Ambiental en México, en http://www.ine.gob.mx/ueajei/ponencias.html 